\title{
The hetero-transplantation of human bone marrow stromal cells carried by hydrogel unexpectedly demonstrates a significant role in the functional recovery in the injured spinal cord of rats
}

Raynald ${ }^{1}$,Yanbin $\mathrm{Li}^{5}$, Hao $\mathrm{Yu}^{3}$, Hua Huang ${ }^{1}$, Muyao Guo ${ }^{4}$, Rongrong $\mathrm{Hua}^{2}$, Fenjun Jiang $^{2}$, Kaihua Zhang ${ }^{1}$, Hailong $\mathrm{Li}^{1}$, Fei Wang ${ }^{6}$, Lusheng $\mathrm{Li}^{3}$, FuZhai Cui ${ }^{4}$, Yihua $\mathrm{An}^{2,3 *}$

*Corresponding Author: Yihua $\mathrm{An}^{2,3}$

First author e-mail address: raynald_liu@yahoo.com

Corresponding author e-mail address:doctoran2010@hotmail.com

1. Beijing Neurosurgical Institute, Capital Medical University, Beijing, 100050, China

2. Department of Stem Cell Transplantation, The General Hospital of Chinese People's Armed Police Forces, Beijing 100039, China

3. Department of Neurosurgery, Beijing Sanbo Brain Hospital, Capital Medical University, Beijing, 100093, China

4. Biomaterials Laboratory, Department of Materials Science and Engineering, TsingHua University, Beijing, 100054, China

5. Beijing Di Tan Hospital, Capital Medical University, Beijing, 100050, China

6. Department of neurosurgery, Inner Mongolia medical university affiliated hospital, Inner mongolia, 010050, China

Keywords: spinal cord injury; bone marrow stromal cell; hyaluronic acid; 
functional recovery; hetero-transplantation

\section{Abstract}

Spinal cord injury (SCI) often causes a disturbance in the microenvironment in the lesion site resulting in sudden loss of sensory and motor function. Transplantation of stem cells provides a promising strategy in the treatment of SCI. But limited growth and immunological incompatibility of the stem cells with the host limits the application of this strategy. In order to get better survival and integration with the host, we employed a hyaluronic acid (HA) based scaffold covalently modified by poly-L-Lysine (PLL) as a vehicle to deliver the human bone marrow stromal cells (BMSCs) to the injured spinal cord of rats. The BMSCs were chosen as an ideal candidate for its advantage of low expression of major histocompatibility complex II. The data unexpectedly showed that the hetero-transplanted cells survived well in the lesion site even at 8 weeks post injury. Both the immunofluorescent and the electrophysiological assay indicated better survival of the transplanted cells and improved axonal growth in SCI rats transplanted with BMSCs in HA-PLL in contrast to the groups without either BMSCs or the HA scaffold transplantation. These promotions may account for the functional recovery assessed by Basso-Beattie-Bresnahan (BBB) locomotor rating scale in the HA-PLL seeded with BMSCs group. These data suggests that hetero-transplantation of human BMSCs delivered by HA scaffold demonstrates a significant role in the functional recovery in 
the injured spinal cord of rats.

\section{Introduction}

Spinal cord injury (SCI) is generally characterized by the deficit in sensory and motor function caudal to the level of injury due to the destruction of neurons and the failure of axonal regeneration in the deteriorated microenvironment in the lesion site. In this microenvironment, massive inflammation, edema, demyelination, cell death, vascular destruction, formation of glial scar and cavity are found (Schwab, 1998; Tator and Fehlings, 1991). As a promising treatment strategy for SCI, cell therapy is employed to replace the injured cells and secrete neurotrophic factors (Mothe and Tator, 2012; Tetzlaff et al., 2011). Several cell based therapeutic studies display evident axonal growth and improvement in functional recovery in rodent SCI models (Johnson et al., 2010; Ritfeld et al., 2012). And the effect is significantly influenced by the immunological incompatibility with the host and inefficient stem cell growth in vivo (Wakayama et al., 2001; Xu et al., 2005).

On account of low expression of major compatibility complex antigens II (MHC-II), rapid propagation and easy accessibility, BMSCs are regarded as an ideal candidate cell type for transplantation(Nakano et al., 2010; Ringden and Le Blanc, 2005). There are mainly two mechanisms by which BMSCs perform their function in the injured neural tissue. One is that the transplanted BMSCs can differentiate into different cell types such as neurons, oligodendrocytes and astrocytes which help to replace the tissue lost (Nandoe Tewarie et al., 2009; Xu et al., 2011). The other is that 
the transplanted cells can release a series of factors that may provide trophic support for the injured tissue in the lesion site (Novikova et al., 2011; Ritfeld et al., 2012). Thus, such a cell type of low antigenicity can be expected to play an important role in the restoration of the injured tissue. And our study unexpectedly showed that the hetero-transplanted human BMSCs survived well in the lesion site even at 8 weeks after injury.

As is mentioned above, the microenvironment in the lesion site is neurotoxic. In an attempt to achieve a neuroprotective microenvironment to improve the survival of transplanted cells, several groups employed biomaterials such as solid scaffolds to deliver the stem cells and showed improved viability of transplanted cells in rat models of SCI(Guo et al., 2012; Kim et al., 2011; Nomura et al., 2006). The promotion of cell survival can be attributed to the hyaluronic acid (HA) in the HA-PLL scaffold which is a key component of the extracellular matrix $(\mathrm{ECM})($ Ren et al., 2009). And the interaction between HA and cells through CD44and RHAMM receptors exerts influences on cell survival and migration (Aruffo et al., 1990; Casini et al., 2010; Martino and Pluchino, 2006; Turley, 1992).

In this study, we employed a HA based scaffold to deliver the human BMSCs to the lesion site of SCI rats. Prior to use, we examined whether the BMSCs survived well in this scaffold. We then investigated the survival, differentiation of the hetero-transplanted BMSCs and the axon regeneration using multiple technologies. Finally, Basso-Beattie-Bresnahan (BBB) locomotors rating scale was employed to test the functional recovery of SCI rats. 


\section{Results}

\subsection{Characterization of human BMSCs and the chemical structure of HA-PLL}

BMSCs were isolated from the posterior superior iliac spine of the donor patient. And cells were collected after adherence and passaged for five times for FCM analysis which aimed to detect the cell purity prior to use. The phenotypes of BMSCs used in our study were positive for CD44 (97.97\%), CD73 (99.99\%), CD90 (99.97\%) and CD105 (98.94\%), and negative for CD11b (0.26\%), CD19 (1.62\%), CD34 (1.42\%) and CD45 (1.08\%; Fig.1A). This is consistent with the previous study(Vaquero and Zurita, 2009). Then the cells were used for transplantation. The HA based scaffold was synthesized in the way as shown (Fig.1B).

\subsection{In vitro survival of human BMSCs in HA-PLL}

Scanning electron microscope (SEM) analysis showed the multi-porous three-dimension ultra-structure of HA-PLL (Fig.2A). This structure was designed to facilitate the axonal outgrowth along the porous structure in the injured tissue. In order to observe the survival of the seeded cells, we transplanted human BMSCs into the HA-PLL hydrogels in the form of cell suspension. When cultured for 3 days, both SEM and optical microscope data indicated that the human BMSCs survived well on the surface of HA-PLL (Fig.2B-F). In addition to this, cell viability assay showed that there was no statistical difference in viability of BMSCs between in media only and in media containing HA-PLL (Fig.2G). This indicates that HA-PLL is not toxic to the BMSCs in vitro. Then the further in vivo experiments were performed. 


\subsection{In vivo survival and differentiation of transplanted human BMSCs in SCI}

At 8 weeks after surgery, immunofluorescence assay was performed to evaluate the survival of hetero-transplanted human BMSCs labeled by 5-bromo-2-deoxyuridine (BrdU) (Li et al., 2008) . Rats treated with BMSCs/HA-PLL showed better survival of

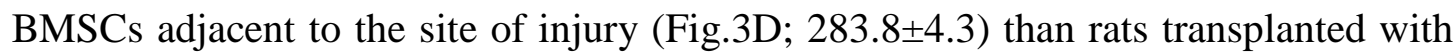
BMSCs in media alone (Fig.3C; 203.4 5.7 ). And difference between these two groups is of statistical significance (Fig.3E; ${ }^{\#} \mathrm{P}<0.01$ ). To determine whether HA promotes the differentiation of $\mathrm{BrdU}^{+}$cells (include the hBMSCs) into different cell types in the lesion site, we performed the immunofluorescence assay by using different cell markers. Our data indicated that the $\mathrm{BrdU}^{+}$cells (include the hBMSCs) mainly differentiated into neurons and astrocytes. Rats engrafted with BMSCs seeded HA-PLL showed a higher percentage of $\mathrm{BrdU}^{+} / \mathrm{NeuN}^{+}$expression $(74.4 \pm 3.2 \%)$ than rats receiving BMSCs only $\left(65.8 \pm 2.8 \%\right.$; Fig. $\left.4 ;^{\#} \mathrm{P}<0.01\right)$. In addition to this, the BMSCs/HA-PLL treated group also displayed a higher percentage of $\mathrm{BrdU}^{+} / \mathrm{GFAP}^{+}$

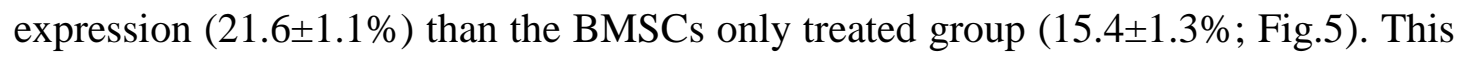
difference is of significance $\left({ }^{\#} \mathrm{P}<0.01\right)$. After the investigation of the survival and differentiation of transplanted human BMSCs in vivo, we then detected the regeneration of injured axons in the lesion site.

\subsection{Axon growth in the injured area}

The immunofluorescence assay was performed to investigate the axons generated in 
the lesion site at 8 weeks after transplantation. Rats treated with BMSCs/HA-PLL showed higher NF positive signals $(65.6 \pm 4.0$; Fig.6G,H) than BMSCs treated group (46.6 \pm 2.7 ; Fig.6E,F; ${ }^{\#} \mathrm{P}<0.01$ ). Both the control group (transplanted with nothing; 19.4 \pm 1.1 ; Fig.6A,B) and the HA-PLL receiving group (34.6 \pm 2.4 ; Fig.6C,D) displayed lower NF positive signals compared to the BMSCs receiving group and the BMSCs/HA-PLL receiving group. In addition to this, TEM was also employed to detect the axonal growth. Few natural axons were detected in the control group at 8 weeks post-SCI (without any transplant; 1.6 \pm 0.6 ; Fig.7A). Rats treated with BMSCs/HA-PLL had more axons (22.4 \pm 1.1 ; Fig.7D) than BMSCs treated group (14.6 \pm 1.1 ; Fig.7 C,E; ${ }^{\#} \mathrm{P}<0.01$ ) or HA-PLL receiving group $\left(8.6 \pm 1.1\right.$; Fig.7 B,E; ${ }^{\text {\# }}$ $\mathrm{P}<0.01)$. These data indicated the evident regeneration of axons in the SCI rats.

\subsection{Assessment of functional recovery of the injured spinal cord}

As an electrophysiological method, the motor evoked potentials (MEPs) assay was performed immediately before, after, 4 weeks and 8 weeks post-operation to assess the functional recovery of the injured spinal cord. Rats implanted with BMSCs/HA-PLL showed shorter latent period of the lower extremity ipsilateral to the injured site than those transplanted with BMSCs alone or HA-PLL (except for immediately before and after surgery) over 8 weeks (Fig.8; $\left.{ }^{\#} \mathrm{P}<0.01\right)($ control $4.78 \pm$ 0.16, HA-PLL: $4.65 \pm 0.24$, BMSCs: $4.22 \pm 0.28$, BMSCs/HA-PLL: $3.98 \pm 0.07)$. In contrast to this, there was no evident change in the latent period between the other two groups (Fig.8). Since the short latent period in the MEP assay is considered well nerve 
conduction, this data demonstrated the role of BMSCs/HA-PLL in the electrophysiological improvement of SCI. To assess the locomotor recovery of SCI rats, the BBB locomotor rating scale was employed. Rats receiving BMSCs/HA-PLL consistently displayed higher score than the other three groups after surgery (Fig.9; $\left.{ }^{\#} \mathrm{P}<0.01\right)$ (control $16.14 \pm 1.07$, HA-PLL: $16.7 \pm 0.82$, BMSCs: $17.13 \pm 0.64$ BMSCs/HA-PLL: $17.63 \pm 0.52$ ). These data, to some extent, demonstrated the beneficial role of HA-PLL delivered human BMSCs in the locomotor recovery of SCI.

\section{Discussion}

Human BMSCs survived well in the newly synthesized HA based scaffold in vitro. Immunofluorecence assay indicated that immune competent rats receiving BMSCs/HA-PLL showed improved survival of transplanted human BMSCs in contrast to the rats receiving BMSCs or HA-PLL alone. Also, the BMSCs delivered by HA-PLL displayed enhanced differentiation into neurons and astrocytes. Both the immunofluorescence and TEM assays indicated that the transplant of BMSCs/HA-PLL promoted the regeneration of axons in the lesion site. In addition to these data, the electrophysiological assay together with the BBB analysis displayed the most evident functional recovery of BMSCs/HA-PLL receiving rats. These results suggested a significant role of the hetero-transplanted human BMCSs carried by hydrogel in the functional recovery in the injured spinal cord of rats.

Most of the studies using BMSCs alone and/or with hyaluronic acid following 
spinal cord injury showed the restorative benefit(Neuhuber et al., 2005; Oliveri et al., 2014). But in these studies, the cells employed were mainly derived from the same species (namely homo-transplantation) (Ballios et al., 2010; Ribatti et al., 2003; Ritfeld et al., 2012). Among them, the two latest studies respectively performed by Chen et al. and Mothe et al. are very similar to our research (Chen et al., 2014; Mothe et al., 2013).And the rats used in these studies were not immune deficient. This kind of transplantation can protect the transplanted cells from being attacked by the immune system of the host. Although the rats were not immune deficient in these studies, they treated rats with immune modulatory medicine such as Taxol(Chen et al., 2014; Zhilaiet al., 2012). Apart from this group of studies, many groups often used cells from different species for transplantation. It's so-called hetero-transplantation. And the rats used in their studies were mainly immune deficient which can facilitate the survival of the transplanted cells.

In our study, human BMSCs were chosen as cell implants for hetero-transplantation due to that BMSCs can be easily obtained from bone marrow and propagate rapidly in vitro (Garcia et al., 2004; Nakano et al., 2010). The difference was that we did not choose the immune deficient rats or gave any immune suppressive treatment. Generally, the effect of hetero-transplantation can be seriously influenced by the incompatibility with the host. But in our study, the hetero-transplanted BMSCs unexpectedly survived well for 8 weeks in immune competent rats and could also play their roles in the injured sites like in other studies which were normally performed in immune deficient rats. This may be mainly attributed to low expression of major histocompatibility complex II in this cell type (Ringden and Le Blanc, 2005). So the hetero-transplantation of this cell type delivered by HA-PLL displays great potential in the clinical therapy which is now largely halted 
by the limited source of cells. This hetero-transplantation of BMSCs has not been performed in immune competent rats previously.

In order to improve the survival of transplanted cells, the HA based scaffold was employed to deliver the BMSCs to the lesion site. The promotion of cell survival can be attributed to the low immunogenicity, three-dimensional network structure of the scaffold and the hyaluronic acid (HA) in the HA-PLL scaffold which is a key component of the extracellular matrix(Zhang et al., 2012). And the interaction between HA and cells through CD44 and RHAMM receptors exerts influences on cell survival and migration(Aruffo et al., 1990; Casini et al., 2010; Martino and Pluchino, 2006; Turley, 1992). Further effort is still required to uncover the other potential mechanisms involved in promoting cell survival.

Immunofluorescence assay using different cell markers indicated that the human BMSCs mainly differentiated into neurons and astrocytes in the lesion site. Rats treated with BMSCs/HA-PLL showed a higher percentage of $\mathrm{BrdU}^{+} / \mathrm{NeuN}^{+}$ expression $(74.4 \pm 3.2 \%)$ than rats receiving BMSCs only $(65.8 \pm 2.8 \%$; Fig.4; $\mathrm{P}<0.01)$. The BMSCs/HA-PLL treated group also displayed a higher percentage of $\mathrm{BrdU}^{+} / \mathrm{GFAP}^{+}$expression $(21.6 \pm 1.1 \%)$ than the BMSCs only treated group (15.4 $\pm 1.3 \%$; Fig.5; P<0.01). And we hardly detected the differentiation of transplanted BMSCs into oligodendrocytes (data not shown here). This data is inconsistent with other study (Chen et al., 2014). This may be a reason for some groups to employ recombinant rat platelet derived growth factor-A covalently modified scaffold to enhance the oligodendrocytes' differentiation(Mothe et al., 2013). 
The mechanism inhibiting the differentiation of BMSCs into oligodendrocytes is still unclear.

In contrast to other groups, we employed multiple technologies to investigate the myelinated axons generated in the lesion site at 8 weeks after transplantation (Chen et al., 2014). The immunofluorescence assay indicated that rats receiving BMSCs/HA-PLL showed more NF positive signals $(65.6 \pm 4.0$; Fig.6G,H) than BMSCs treated group (46.6 \pm 2.7 ; Fig.6E,F; $\mathrm{P}<0.01$ ). The TEM analysis demonstrated that Rats treated with BMSCs/HA-PLL had more axons $(22.4 \pm 1.1$; Fig.7D) than BMSCs treated group $(14.6 \pm 1.1$; Fig.7 C,E; $\mathrm{P}<0.01$ ) or HA-PLL receiving group (8.6 $\pm 1.1 ;$ Fig.7 B,E; $\mathrm{P}<0.01)$. These data suggested the evident role of BMSCs/HA-PLL in the regeneration of axons in SCI rats and was to some extent consistent with another study (Chen et al., 2014). Here arises a question why BMSCs/HA-PLL receiving group showed more evident improvement in axon growth without apparent oligodendrocytes differentiation of BMSCs. Maybe a series of neurotrophic factors released by newly generated astrocytes can account for this improvement.

As a relative supplement to other studies (Chen et al., 2014; Mothe et al., 2013), we also performed the motor evoked potentials (MEPs) assay at different time points to assess the functional recovery of the injured spinal cord. Rats implanted with BMSCs/HA-PLL showed shorter latent period of the lower extremity ipsilateral with the injured site than those transplanted with BMSCs or HA-PLL alone (except for immediately before and after surgery) over 8 weeks (Fig.8; $\mathrm{P}<0.01$ ). This data 
demonstrated the role of BMSCs/HA-PLL in the electrophysiological improvement of SCI and was in accordance with the data of BBB. Like other groups (Chen et al., 2014; Mothe et al., 2013), the BBB locomotor rating scale was employed to assess the locomotor recovery of SCI rats. Rats receiving BMSCs/HA-PLL continually displayed higher score at weeks 1-8 after surgery than the other three groups since a week after surgery (Fig.9; $\mathrm{P}<0.01$ ). These data demonstrated the role of HA-PLL delivered human BMSCs in the locomotor recovery of SCI. And this data was not consistent with another study (Mothe et al., 2013). The usage of different scaffolds and cell types could be employed to explain the inconsistence of BBB data.

\section{Experimental procedures}

\subsection{Preparation of BMSCs}

Ethical approval was obtained from The General Hospital of Chinese People's Armed Police Forces Ethics Committee, China, and written informed consent was obtained from the bone marrow donors.

Bone marrow was obtained from iliac bone of donors. The cells were plated at a density of $1 \times 10^{5} / \mathrm{cm}^{2}$ in Dulbecco's modified Eagle's medium / nutrient mixture F-12 (GIBCO, USA) supplemented with 15\% fetal bovine serum (GIBCO, USA), and incubated at $37^{\circ} \mathrm{C}$ in an atmosphere containing $5 \% \mathrm{CO}_{2}$. The medium was replaced with the fresh medium every third day. The cells were digested with trypsin (GIBCO, USA) and passaged upon reaching $90 \%$ confluence. At fifth passage, BMSCs were collected. BMSCs were labeled with $5 \mu \mathrm{m}$ bromodeoxyuridine (BrdU, Roche, Basel, 
Switzerland) 24 hours prior to transplantation. The cells were suspended with normal saline to a concentration of $1 \times 10^{5}$ cell $/ \mathrm{ml}$. The percentage of cell viability was determined by averaging counts from 5 different randomly chosen microscopic fields. The flow cytometry was performed to detect the cell purity. The percentage of CD105, CD90, CD73 and CD44 were all higher than 95\%, while the percentage of CD19, CD45, CD11b and CD34 were all lower than 5\%. Then the cells were used for transplantation.

\subsection{Preparation of HA-PLL}

HA sodium salt (MW, 425g/mol) was purchased from Shandong FuredaBiochem (Fureda, Jinan, Shandong, China). Sodium salt was dissolved in distilled water for a concentration of $10 \mathrm{mg} / \mathrm{ml}$. Poly-lysine(Sigma, USA) was added to the solution and the ratio (w/w) of HA: poly-lysine is 5:1. The $\mathrm{pH}$ of the solution was adjusted to 4.75 by adding 0.1M HCl. 1-Ethyl-N,N-dimethy-laminopropyl carbodiimide (EDC, $0.10 \mathrm{~g}$, final concentration $1.25 \mathrm{mg} / \mathrm{ml}$ ) was used as a cross-linking agent. After stirring thoroughly the mixture was allowed to gel at room temperature. The hydrogel obtained was lyophilized at $-20^{\circ} \mathrm{C}$ for 24 hours. The lyophilized hydrogel was washed with PBS five times. Then, the hydrogel was sterilized with $70 \%$ alcohol overnight, and then rinsed extensively with sterilized PBS. Then, the hydrogel was coated with poly-lysine in a final concentration of $2 \mathrm{mg} / \mathrm{mL}$ by stirring for 4 hours and rinsing extensively with sterilized PBS. 


\subsection{Establishment of rat model with lateral hemi-transected spinal cord and the transplantation of BMSCs}

The associated animal experiments were performed according to the Guidelines for the Use and Care of Experimental Animals and this study were approved by Beijing Neurosurgical Institute ethics committee (Permit Number: No.201301020). Efforts were made to decrease animal suffering during the procedures.

Female Spraque-Dawley rats (average weight: 200-250g, $n=33$ ) were obtained from the Vital River Company. The rats were randomly divided into 4 groups. Rats in group A were only injured without any implantation (control, $n=7$ ). Rats in group B were implanted with HA-PLL $(n=10)$. Rats in group $C$ were transplanted with BMSCs $(\mathrm{n}=8)$. Rats in group D were transplanted with HA-PLL carried BMSCs $(\mathrm{n}=$ 8). All the experiments involved in the study were completely blinded to the animal grouping. The SD rats were bred in animal rooms where temperature and humidity could be controlled.

Intra-peritoneal anesthesia was done with chloral hydrate solution $(0.4 \mathrm{ml} / 100 \mathrm{~g})$, a laminectomy was performed at T8-T9 vertebrae level under a surgical microscope (Sight 66 Su Zhou). A dorsal midline incision was made and the spinal cord was cut longitudinally along its dorsal vessel followed by two hemi-sections $2 \mathrm{~mm}$ apart on the right side. The tissue segment between the two cuts was removed to create a space for the graft. The hydrogel implant was sized to adapt to the dimension of the cavity.

The rats were randomly divided into 4 groups. Rats in group A were only injured without any implantation (control, $\mathrm{n}=7$ ). Rats in group $\mathrm{B}$ were implanted with 
HA-PLL $(n=10)$. Rats in group C were transplanted with $1 \times 10^{5}$ BMSCs $(n=8)$. Rats in group D were transplanted with $1 \times 10^{5}$ BMSCs carried by HA-PLL $(n=8)$. Then the incision was closed by suturing the dura, muscles and skin in order. Antibiotic (penicillin 10000 unit) was given after the surgery and the rats were observed until awake. Manual bladder and peritoneal exercise was performed twice a day until recovery of the bladder and intestinal reflex.

\subsection{Electrophysiology: motor evoked potential (MEP)}

Evoked potential is the electrical signal generated by the nervous system in response to stimuli. The measurement of motor evoked potential has been performed in the diagnosis and prognosis of various neurological disorders. Motor evoked potential (MEP) was measured using Neurosoft electrophysiology monitoring system (neuron spectrum 5, Russia). Motor evoked potential (MEP) was obtained using stainless steel needle electrodes, Neurosoft software. Rats were anesthetized with chloral hydrate solution $(0.4 \mathrm{~mL} / 100 \mathrm{~g})$. Stimulating electrode was inserted into the scalp to stimulate the low extremity muscle, and recording electrode was inserted in the tibial muscle. Reference electrodes were inserted subcutaneously above the nostril, the peritoneum and the tail. MEP was obtained by electrical stimulation at $20 \mathrm{~Hz}, 2 \mathrm{~mA}$ and $2 \mathrm{mV}$ and the latent period of MEP was analyzed.

\subsection{Immunofluorescent assay of axonal growth, survival and differentiation} of BMSCs. 
After 8 weeks, the rats were anesthetized through intra-peritoneal injection of chloral hydrate solution $(0.4 \mathrm{ml} / 100 \mathrm{~g})$, the spinal cords at the level of T6-T10 were collected, and fixed in $4 \%$ paraformaldehyde containing $30 \%$ sucrose at $4{ }^{\circ} \mathrm{C}$ for 48 hours, and embedded in OCT (Sakura Finetechnical, Japan). Then serial $15 \mu \mathrm{m}$ frozen longitudinal sections were collected. Immunofluorescent assay was performed on $15 \mu \mathrm{m}$ section stained with the following antibodies: anti-bromodeoxyuridine (anti-BrdU; ABBIOTEC; 1:100 dilution); anti-neuron specific marker (anti-NeuN; Millipore; 1:200 dilution); anti-glial fibrillary acidic protein (anti-GFAP; Millipore; 1:400 dilution); anti-neurofilament (anti-NF; Abcam; 1:200 dilution), 4',6-diamidino-2-phenylindole (DAPI, Invitrogen, USA). Sections of spinal cord were imaged at $100 \times$ and $200 \times$ magnifications using a confocal microscope (Leica SP5, Germany). BrdU staining was performed to check the survival of the BMSCs. Double immunofluorescent assay was performed to determine whether the $\mathrm{BrdU}^{+}$cells (include the hBMSCs) differentiate into other cell types. NF staining was performed to detect axon growth in the injured area.

\subsection{Ultra-structure analysis by both Transmission and Scanning Electron Microscope}

After 8 weeks, the spinal cords of each group were examined by transmission electron microscopy (Hitachi TEM, Japan). The rats were anesthetized and perfused through the heart with $4 \%$ paraformaldehyde, the spinal cord tissue was fixed in $2.5 \%$ glutaraldehyde and $2 \%$ paraformaldehyde. Ultrathin sections were achieved with an 
ultramicrotome (Leica EM UC6, Germany) and stained with uranyl acetate and lead citrate. Observation was performed by TEM (Hitachi). For observation by SEM, the fixed samples were dehydrated using a gradient of alcohol. After coating with hexamethyldisilazane amine alkoxy, the samples were examined by SEM (Hitachi TM-100, Japan).

\subsection{Neurobehavioral testing}

BBB open-field locomotor score: locomotor recovery of the animals was assessed by two independent observers in an open field (diameter of plastic pool: $90 \mathrm{~cm}$ ) using the 21-point Basso, Beattie and Bresnahan (BBB) open-field locomotor score from 1 to 8 weeks after SCI. The BBB scale was used to assess hind-limb locomotor recovery including joint movements, stepping ability, coordination and trunk stability. The function of ipsilateralhind-limb was detected. Testing was done every week on a blinded basis and the duration of each session was 2 min per rat.

\subsection{Quantitative cell analysis}

All quantitative cell analyses were performed in a blinded fashion. For quantitative analyses of the survival, differentiation of transplanted cells and new regenerated axons, all $\mathrm{BrdU}^{+}, \mathrm{BrdU}^{+} / \mathrm{NeuN}^{+}, \mathrm{BrdU}^{+} / \mathrm{GFAP}^{+}, \mathrm{NF}^{+}$were counted in longitudinal sections (section thickness $=15 \mu \mathrm{m}$ ). The data of percentage of positive cells for each antibody was achieved from 5 different randomly chosen microscopic fields. The sections were examined under a confocal laser scanning microscope (Leica SP5, 
Germany) 8 weeks post operation. The percentage of double-labeled cells was expressed as a proportion of BrdU+ transplanted cells. BrdU positive cells were counted to obtain the percentage of BrdU cells co-localized with cell type specific markers (NeuN, GFAP) by double staining. Cells and new generated axons were counted with NIS-Elements Imaging Software (Nikon). The data of the number of new generated axons in TEM results was achieved from 5 different randomly chosen field in 7000×magnification.

\subsection{Statistical analysis}

All the data were expressed as mean \pm standard deviation (SD). Statistics were calculated with software SPSS 13.0. Differences between groups were compared with one-way ANOVA followed by the appropriate post-hoc test. Differences of repeated measures were analyzed with multivariate ANOVA. A significant difference was indicated by $\mathrm{P}<0.05$ and $\mathrm{P}<0.01$.

\section{Conclusions}

Human BMSCs survived well in the newly synthesized HA based scaffold in vitro. In addition to this, rats receiving human BMSCs/HA-PLL showed improved survival of transplanted human BMSCs in vivo. Also, the BMSCs delivered by HA-PLL promotes the differentiation of the $\mathrm{BrdU}^{+}$cells (include the hBMSCs) into neurons and astrocytes. And the transplantation of BMSCs/HA-PLL promoted the regeneration of axons in the lesion site. In addition to these data, the 
electrophysiological assay together with the BBB analysis displayed the most evident functional recovery of BMSCs/HA-PLL receiving rats. These results suggested a significant role of the hetero-transplanted human bone marrow stromal cells carried by hydrogel in the functional recovery in the injured spinal cord of rats.

\begin{abstract}
Abbreviations
BBB scale, the Basso Beattie Bresnahanlocomotor rating scale; BMSCs, bone marrow stromal cells; BrdU, bromodeoxyuridine; EDC, 1-Ethyl-N,N-dimethy-laminopropyl carbodiimide; GFAP, glial fibrillary acidic protein; HA, hyaluronic acid; MEP, motor evoked potential; MHC-II, major histocompatibility complex antigen II; NeuN, neuronal nuclear antigen; NF, neurofilament; PLL, poly-L-Lysine; SCI, Spinal cord injury; SD rat, Spraque-Dawley rat; SEM, scanning electron microscope; TEM transmission electron microscope.
\end{abstract}

\title{
Acknowledgements
}

This study was supported by the Beijing National Science Foundation, Comparison of human diseases of the Ministry of Health, Key Laboratory of Medicine Research Fund and the Strategic emerging industries in Guangdong Province, the core technology research. The authors declared that they had no competing interests.

\section{References}

Aruffo, A., Stamenkovic, I., Melnick, M., Underhill, C.B., Seed, B., 1990. CD44 is the principal cell surface receptor for hyaluronate. Cell. 61, 1303-13. 
Ballios, B.G., Cooke, M.J., van der Kooy, D., Shoichet, M.S., 2010. A hydrogel-based stem cell delivery system to treat retinal degenerative diseases. Biomaterials. 31, 2555-64.

Casini, P., Nardi, I., Ori, M., 2010. RHAMM mRNA expression in proliferating and migrating cells of the developing central nervous system. Gene Expr Patterns. 10, 93-7.

Chen, J., Zhang, Z., Liu, J., Zhou, R., Zheng, X., Chen, T., Wang, L., Huang, M., Yang, C., Li, Z., Yang, C., Bai, X., Jin, D., 2014. Acellular spinal cord scaffold seeded with bone marrow stromal cells protects tissue and promotes functional recovery in spinal cord-injured rats. J Neurosci Res. 92, 307-17.

Garcia, R., Aguiar, J., Alberti, E., de la Cuetara, K., Pavon, N., 2004. Bone marrow stromal cells produce nerve growth factor and glial cell line-derived neurotrophic factors. Biochem Biophys Res Commun. 316, 753-4.

Guo, X., Zahir, T., Mothe, A., Shoichet, M.S., Morshead, C.M., Katayama, Y., Tator, C.H., 2012. The effect of growth factors and soluble Nogo-66 receptor protein on transplanted neural stem/progenitor survival and axonal regeneration after complete transection of rat spinal cord. Cell Transplant. 21, 1177-97.

Johnson, P.J., Tatara, A., Shiu, A., Sakiyama-Elbert, S.E., 2010. Controlled release of neurotrophin-3 and platelet-derived growth factor from fibrin scaffolds containing neural progenitor cells enhances survival and differentiation into neurons in a subacute model of SCl. Cell Transplant. 19, 89-101.

Kim, H., Zahir, T., Tator, C.H., Shoichet, M.S., 2011. Effects of dibutyryl cyclic-AMP on survival and neuronal differentiation of neural stem/progenitor cells transplanted into spinal cord injured rats. PLoS One. 6, e21744.

Li, N., Yang, H., Lu, L., Duan, C., Zhao, C., Zhao, H., 2008. Comparison of the labeling efficiency of BrdU, Dil and FISH labeling techniques in bone marrow stromal cells. Brain Res. 1215, 11-9.

Martino, G., Pluchino, S., 2006. The therapeutic potential of neural stem cells. Nat Rev Neurosci. 7, 395-406.

Mothe, A.J., Tator, C.H., 2012. Advances in stem cell therapy for spinal cord injury. J Clin Invest. 122, 3824-34.

Mothe, A.J., Tam, R.Y., Zahir, T., Tator, C.H., Shoichet, M.S., 2013. Repair of the injured spinal cord by transplantation of neural stem cells in a hyaluronan-based hydrogel. Biomaterials. 34, 3775-83.

Nakano, N., Nakai, Y., Seo, T.B., Yamada, Y., Ohno, T., Yamanaka, A., Nagai, Y., Fukushima, M., Suzuki, Y., Nakatani, T., Ide, C., 2010. Characterization of conditioned medium of cultured bone marrow stromal cells. Neurosci Lett. 483, 57-61.

Nandoe Tewarie, R.D., Hurtado, A., Ritfeld, G.J., Rahiem, S.T., Wendell, D.F., Barroso, M.M., Grotenhuis, J.A., Oudega, M., 2009. Bone marrow stromal cells elicit tissue sparing after acute but not delayed transplantation into the contused adult rat thoracic spinal cord. J Neurotrauma. 26, 2313-22.

Neuhuber, B., Timothy Himes, B., Shumsky, J.S., Gallo, G., Fischer, I., 2005. Axon growth and recovery of function supported by human bone marrow stromal cells in the injured spinal cord exhibit donor variations. Brain Res. 1035, 73-85.

Nomura, H., Tator, C.H., Shoichet, M.S., 2006. Bioengineered strategies for spinal cord repair. J Neurotrauma. 23, 496-507.

Novikova, L.N., Brohlin, M., Kingham, P.J., Novikov, L.N., Wiberg, M., 2011. Neuroprotective and 
growth-promoting effects of bone marrow stromal cells after cervical spinal cord injury in adult rats. Cytotherapy. 13, 873-87.

Oliveri, R.S., Bello, S., Biering-Sorensen, F., 2014. Mesenchymal stem cells improve locomotor recovery in traumatic spinal cord injury: systematic review with meta-analyses of rat models. Neurobiol Dis. 62, 338-53.

Ren, Y.J., Zhou, Z.Y., Cui, F.Z., Ying, W., Zhao, J.P., Xu, Q.Y., 2009. Hyaluronic Acid/Polylysine Hydrogel as a Transfer System for Transplantation of Neural Stem Cells. Journal of Bioactive and Compatible Polymers. 24, 56-62.

Ribatti, D., Conconi, M.T., Nico, B., Baiguera, S., Corsi, P., Parnigotto, P.P., Nussdorfer, G.G., 2003. Angiogenic response induced by acellular brain scaffolds grafted onto the chick embryo chorioallantoic membrane. Brain Res. 989, 9-15.

Ringden, O., Le Blanc, K., 2005. Allogeneic hematopoietic stem cell transplantation: state of the art and new perspectives. APMIS. 113, 813-30.

Ritfeld, G.J., Nandoe Tewarie, R.D., Vajn, K., Rahiem, S.T., Hurtado, A., Wendell, D.F., Roos, R.A., Oudega, M., 2012. Bone marrow stromal cell-mediated tissue sparing enhances functional repair after spinal cord contusion in adult rats. Cell Transplant. 21, 1561-75.

Schwab, M.E., 1998. Regenerative Nerve Fiber Growth in the Adult Central Nervous System. News Physiol Sci. 13, 294-298.

Tator, C.H., Fehlings, M.G., 1991. Review of the secondary injury theory of acute spinal cord trauma with emphasis on vascular mechanisms. J Neurosurg. 75, 15-26.

Tetzlaff, W., Okon, E.B., Karimi-Abdolrezaee, S., Hill, C.E., Sparling, J.S., Plemel, J.R., Plunet, W.T., Tsai, E.C., Baptiste, D., Smithson, L.J., Kawaja, M.D., Fehlings, M.G., Kwon, B.K., 2011. A systematic review of cellular transplantation therapies for spinal cord injury. J Neurotrauma. 28, 1611-82.

Turley, E.A., 1992. Hyaluronan and cell locomotion. Cancer Metastasis Rev. 11, 21-30.

Vaquero, J., Zurita, M., 2009. Bone marrow stromal cells for spinal cord repair: a challenge for contemporary neurobiology. Histol Histopathol. 24, 107-16.

Wakayama, T., Tabar, V., Rodriguez, I., Perry, A.C., Studer, L., Mombaerts, P., 2001. Differentiation of embryonic stem cell lines generated from adult somatic cells by nuclear transfer. Science. 292, 740-3.

Xu, R.H., Peck, R.M., Li, D.S., Feng, X., Ludwig, T., Thomson, J.A., 2005. Basic FGF and suppression of BMP signaling sustain undifferentiated proliferation of human ES cells. Nat Methods. 2, 185-90.

Xu, X., Geremia, N., Bao, F., Pniak, A., Rossoni, M., Brown, A., 2011. Schwann cell coculture improves the therapeutic effect of bone marrow stromal cells on recovery in spinal cord-injured mice. Cell Transplant. 20, 1065-86.

Zhang, X.Y., Xue, H., Liu, J.M., Chen, D., 2012. Chemically extracted acellular muscle: a new potential scaffold for spinal cord injury repair. J Biomed Mater Res A. 100, 578-87.

\section{Figures}

\section{Figure 1}


Immuno-phenotypes of BMSCs and the synthesis of HA-PLL scaffold. (A)CD45 negative (1.08\%), CD34 negative (1.42\%), CD19 negative (1.62\%), CD11b negative (0.26\%) CD105positive (98.94\%), CD73 (99.99\%) positive, CD90 positive (99.97\%), CD44 positive (97.97\%). (B) This is the illustration of the synthesis of HA-PLL scaffold.

\section{Figure 2}

The in vitro survival of BMSCs observed by optical and electron microscope. (A) 3D multi-porous structure of HA-PLL. (B,C) BMSCs were co-cultured with HA-PLL for 3 days in vitro. BMSCs well survived and adhered to the surface of HA-PLL (BMSCs were indicated by arrow). Scale bar: A(1 mm), B(30 um), C(10 um). (D) BMSCs cultured in media. (E) BMSCs co-cultured with HA-PLL.

\section{Figure 3}

The in vivo survival of BMSCs. (A, B) No obvious signal was detected in this non-transplanted group and HA-PLL group. (C, D) The signal of BrdU labeled BMSCs (green, white arrow) was detected in the injured area which was the target site of transplantation. (E) Quantification of $\mathrm{BrdU}^{+}\left({ }^{\#} \mathrm{P}<0.01\right.$ versus all other three groups, ${ }^{*} \mathrm{P}<0.01$ versus the control group). The dotted line marks the border between the host spinal cord and the graft (H, hydrogel implanted; $\mathrm{T}$, host tissue; L, Lesion). Scale bar in $(A-D)=250 \mu \mathrm{m}$. This experiment was repeated three times. 


\section{Figure 4}

The differentiation of BMSCs into neurons at 8 weeks after transplantation.(A-H)

The immune-staining of BMSCs using BrdU and NeuN. BrdU signals (green) co-localized with NeuN signals (a marker of neurons; red; indicated by arrow). (I)The difference in the number of $\mathrm{BrdU}^{+} / \mathrm{NeuN}^{+}$cells between these two groups is of statistical significance $\left({ }^{\#} \mathrm{P}<0.01\right)$. These data suggested that BMSCs/HA-PLL significantly enhanced the differentiation of the $\mathrm{BrdU}^{+}$cells (include the hBMSCs) into neurons. Scale bar in $(\mathrm{A}-\mathrm{H})=75 \mu \mathrm{m}$. This experiment was repeated three times.

\section{Figure 5}

The differentiation of BMSCs into astrocytes cell at 8 weeks after transplantation.(A-H) The immune-staining of BMSCs using BrdU and GFAP. BrdU signals (green) co-localized with GFAP signals （a glial cell marker; red; indicated by arrow). (I) The difference in the number of $\mathrm{BrdU}^{+} / \mathrm{GFAP}^{+}$cells between these two groups is of statistical significance $\left({ }^{\#} \mathrm{P}<0.01\right)$. These data suggested that BMSCs/HA-PLL significantly enhanced the differentiation of the $\mathrm{BrdU}^{+}$cells (include the hBMSCs) into astrocytes. Scale bar in $(\mathrm{A}-\mathrm{H})=75 \mu \mathrm{m}$. This experiment was repeated three times.

\section{Figure 6}

The immunofluorescence assay of axons in injured spinal cord at 8 weeks after operation. Axons stained with anti-NF (red) in longitudinal sections at 8 weeks after 
SCI. We compared the expression of NF in the lesion site. (A) Control without any treatment, (B) HA-PLL receiving group,(C) BMSCs receiving group, (D) BMSCs/HA-PLL treated group. (E) The differences in $\mathrm{NF}^{+}$staining in 4 groups are of statistical significance $\left({ }^{\#} \mathrm{P}<0.01\right.$ versus all other three groups, $* \mathrm{P}<0.01$ versus the control group). The dotted line marks the border between the host spinal cord and the graft $(\mathrm{H}$, Hemi-transected area; $T$, host tissue; $\mathrm{S}$, scar tissue $)$. Scale bar in (A,C,E,G) = $250 \mu \mathrm{m}$, scale bar in $(\mathrm{B}, \mathrm{D}, \mathrm{F}, \mathrm{G})=75 \mu \mathrm{m}$. This experiment was repeated three times.

\section{Figure 7}

The detection of newly generated axons by TEM at 8 weeks after transplantation.(A) This group served as a control here. No natural axons were detected here (indicated by arrow). (B-D) A lot of newly generated axons were detected (indicated by arrow). (I)The differences in axon quantity between 4 groups are of statistical significance $\left({ }^{\#} \mathrm{P}<0.01\right.$ versus all other three groups, $* \mathrm{P}<0.01$ versus the control group). Scale bar in (A-D) $=5 \mu \mathrm{m}$. This experiment was repeated three times.

\section{Figure 8}

The electrophysiological recovery post surgery. These four groups included control group (without any treatment), HA-PLL implanted group, BMSCs transplanted group, BMSCs/HA-PLL receiving group. Among these groups, the latent period of BMSCs/HA-PLL receiving group was closest to the normal level at 8 weeks after 
operation. ( ${ }^{*} \mathrm{P}<0.01$ versus the control group, $* \mathrm{P}<0.05$ versus the control group). This experiment was repeated three times.

\section{Figure 9}

Behavioral assessment using Basso-Beattie-Bresnahan(BBB) locomotor rating scale. The BBB analysis was performed continually since the first week after surgery. BBB analysis indicated that BMSCs/HA-PLL treated group showed the greatest functional recovery compared to control or those treated with HA-PLL or BMSCs alone ( ${ }^{\#} \mathrm{P}<0.01$ versus the control group, ${ }^{*} \mathrm{P}<0.05$ versus the control group). This experiment was repeated three times. 
A
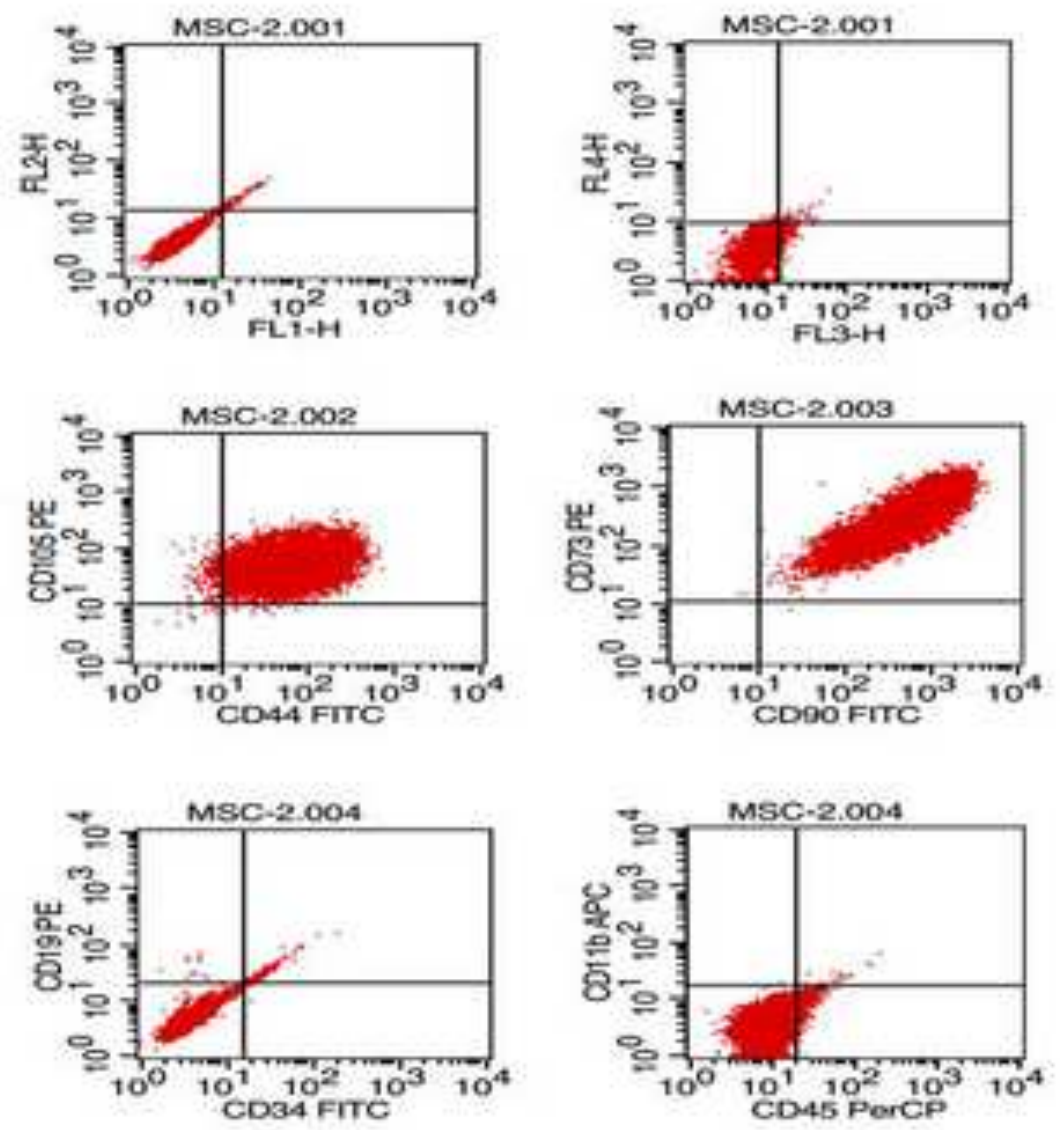

B

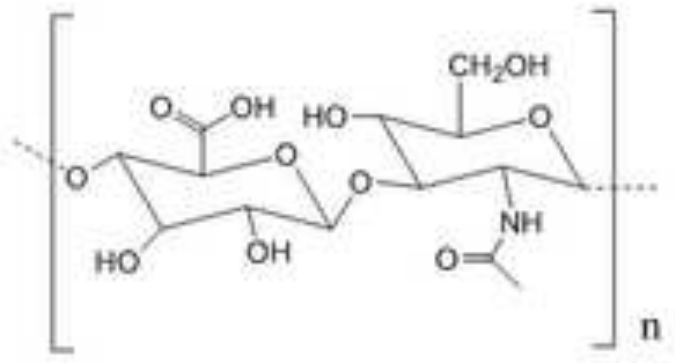

HA

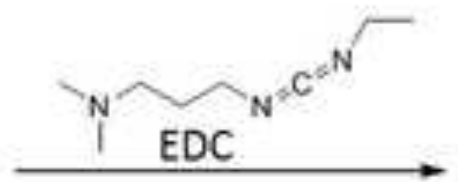<smiles>CC(C)(C)C(=O)[C@@H](N)CCCCNC(F)(F)F</smiles>

PLL

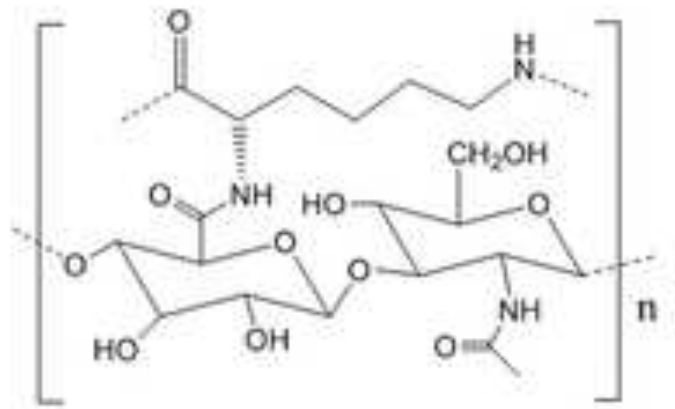

HA-PLL 

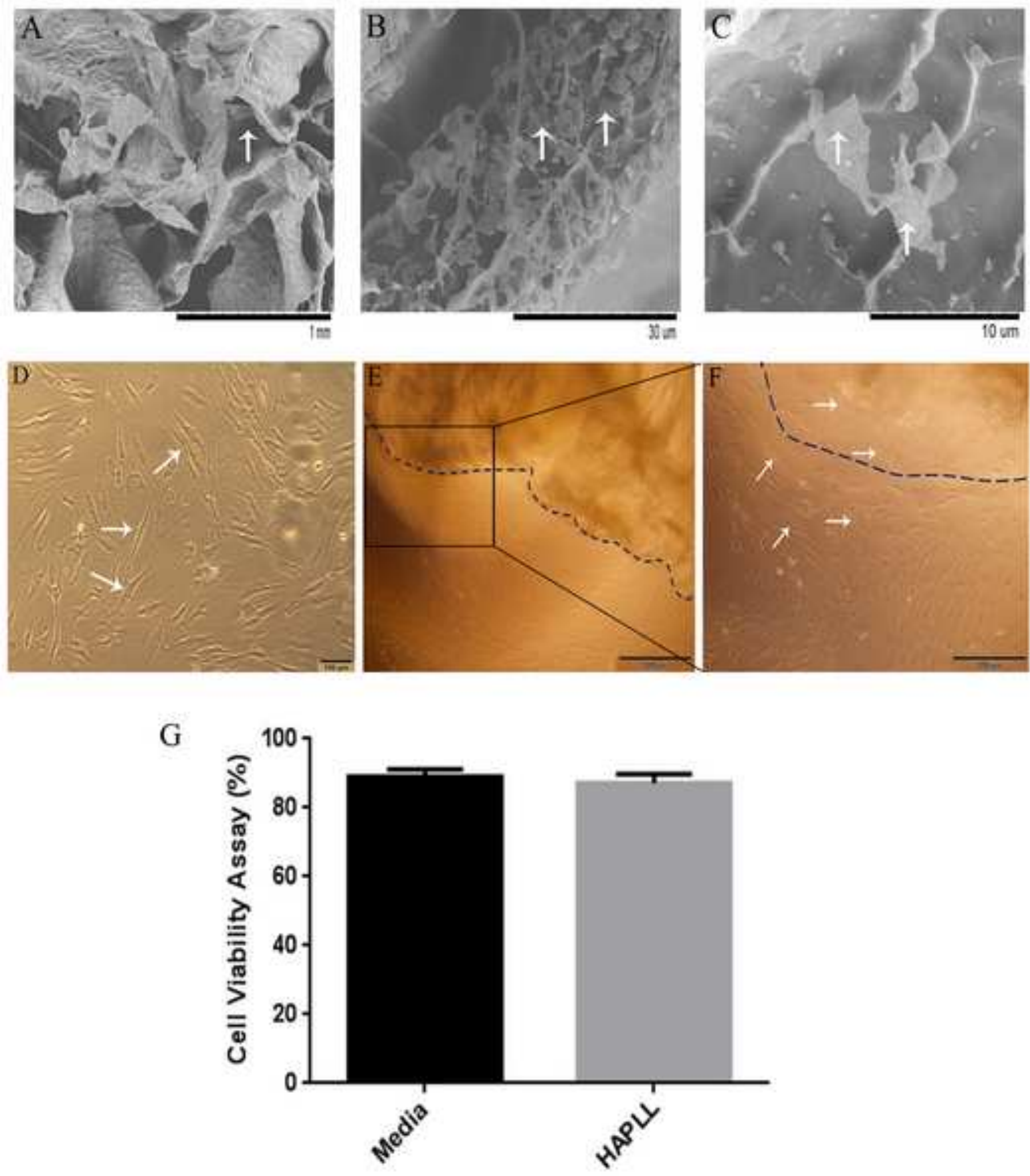

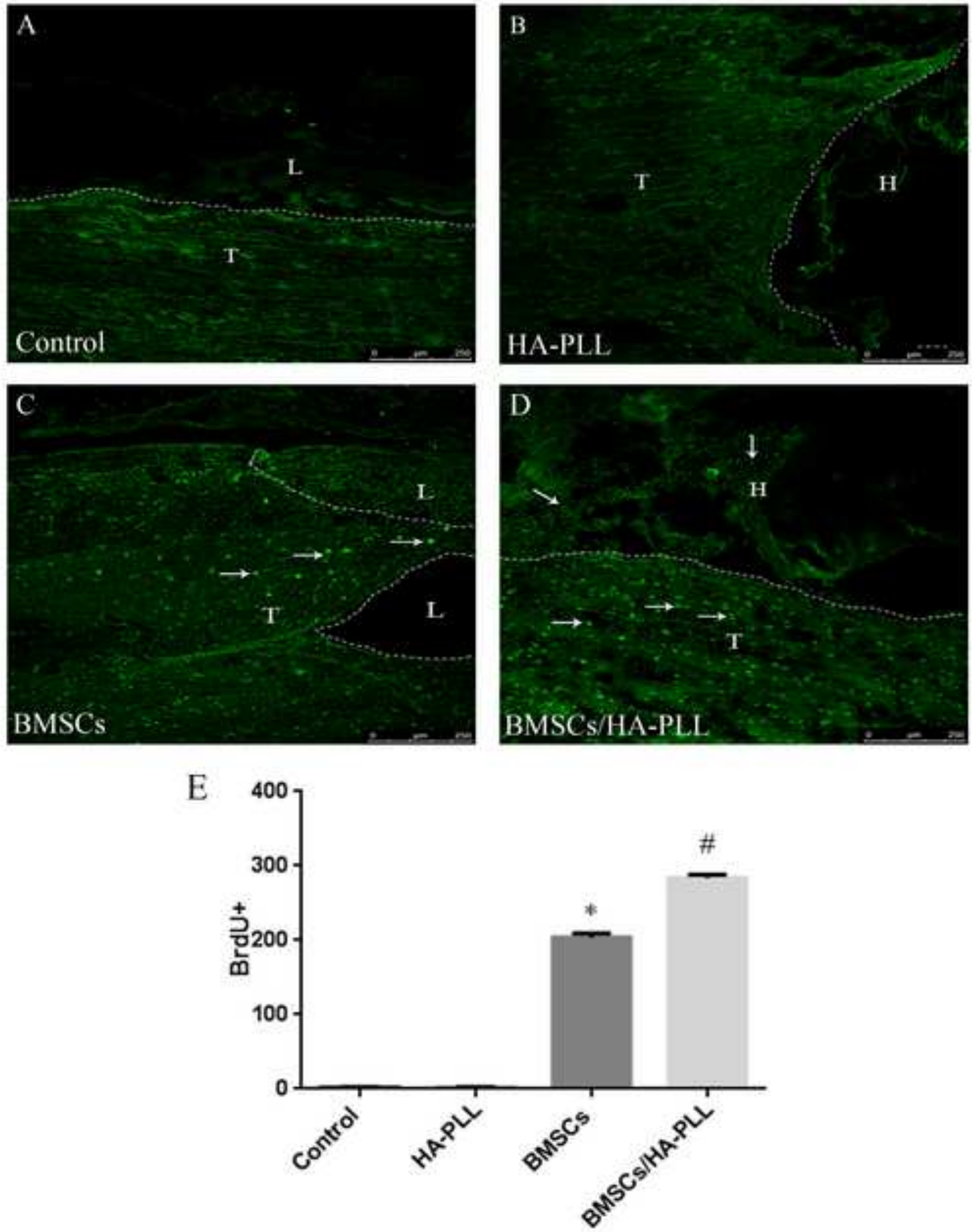
BrdU

A

,

4

BMSCs

E

BMSCSHA-PLL 으르. Is
NeuN

B

C

DAPI

BrdU/NeuN/DAPI

D

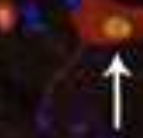

4

e. in is $\mathrm{H}$

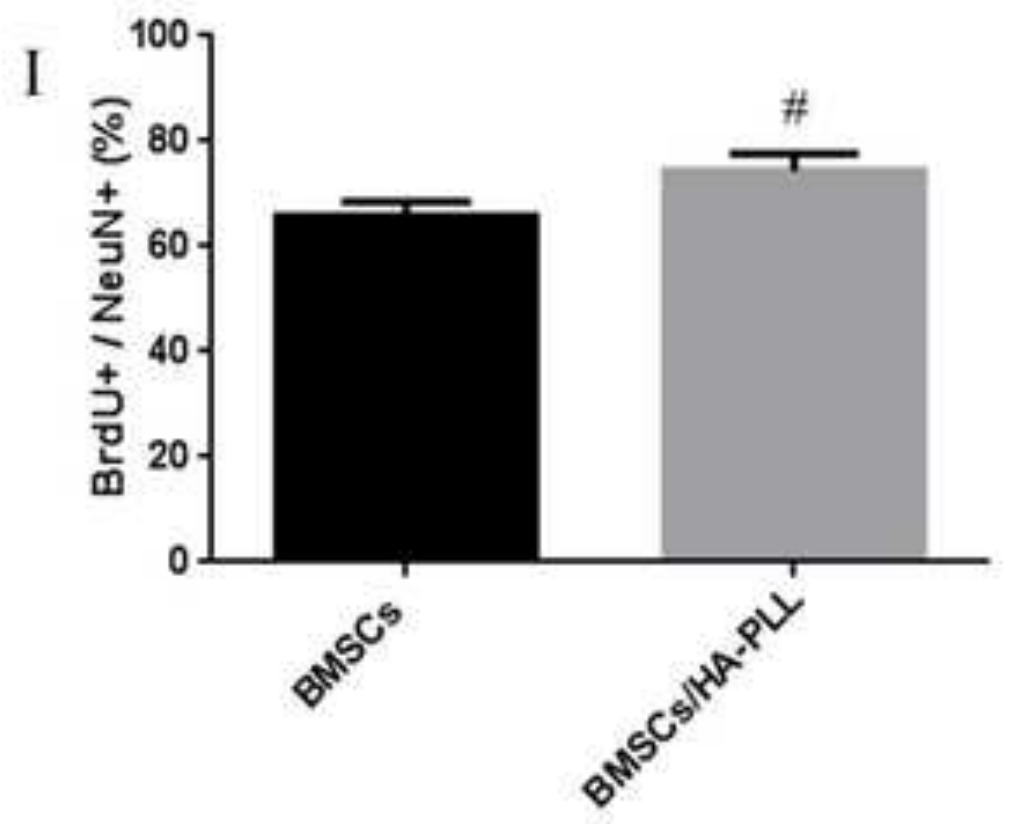


BrdU
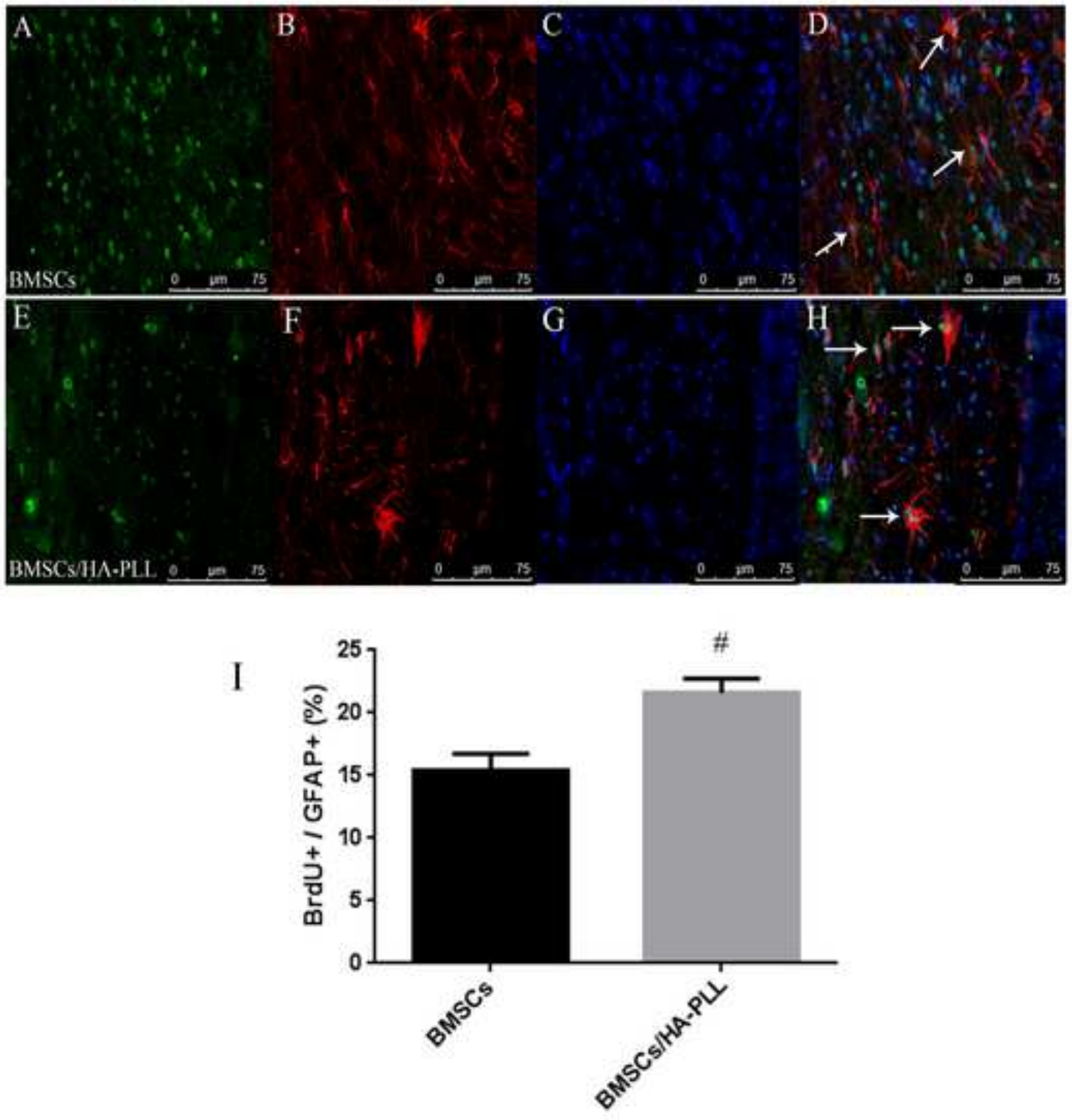

Brdt/GFAPJDAPI 

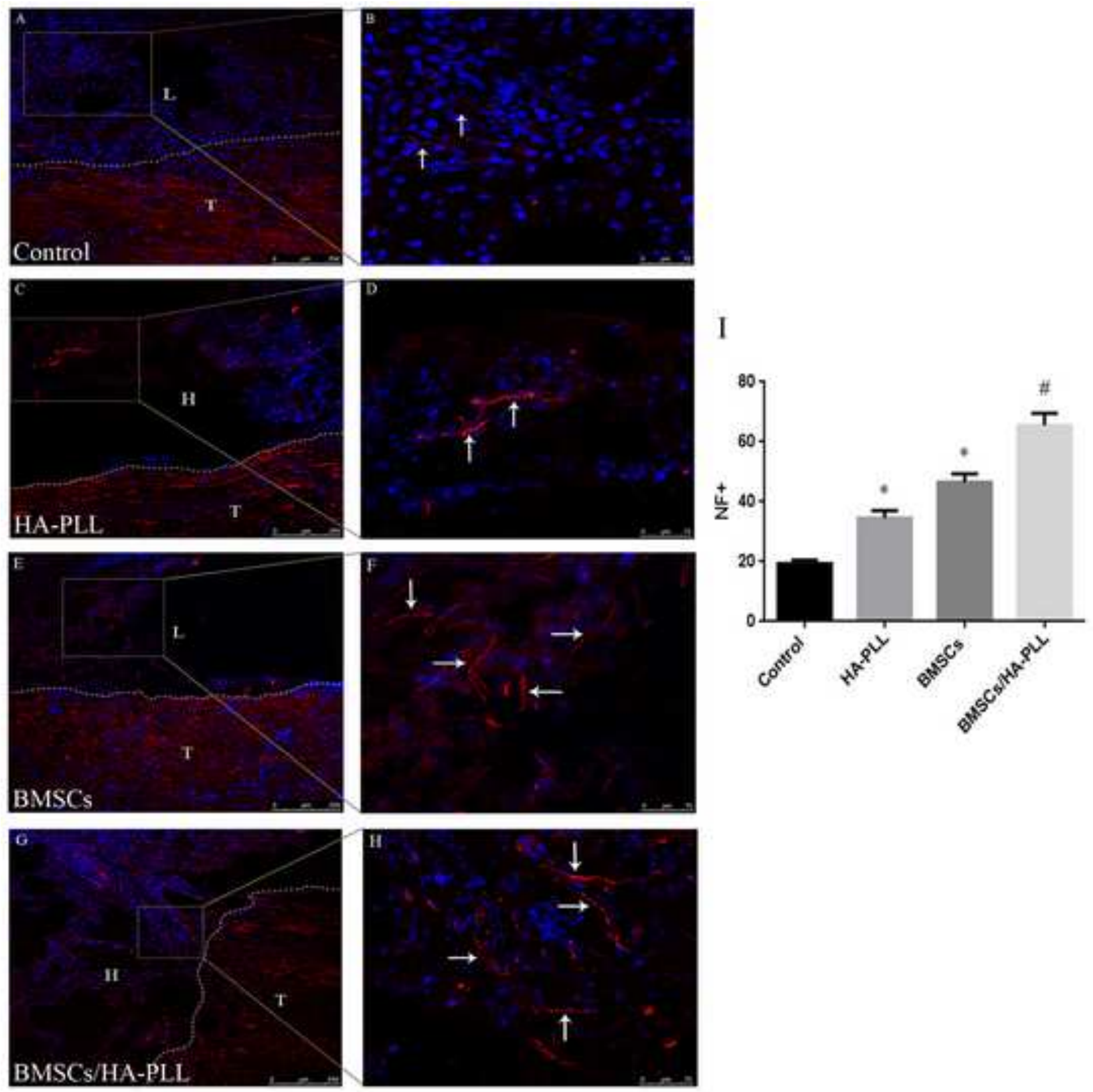

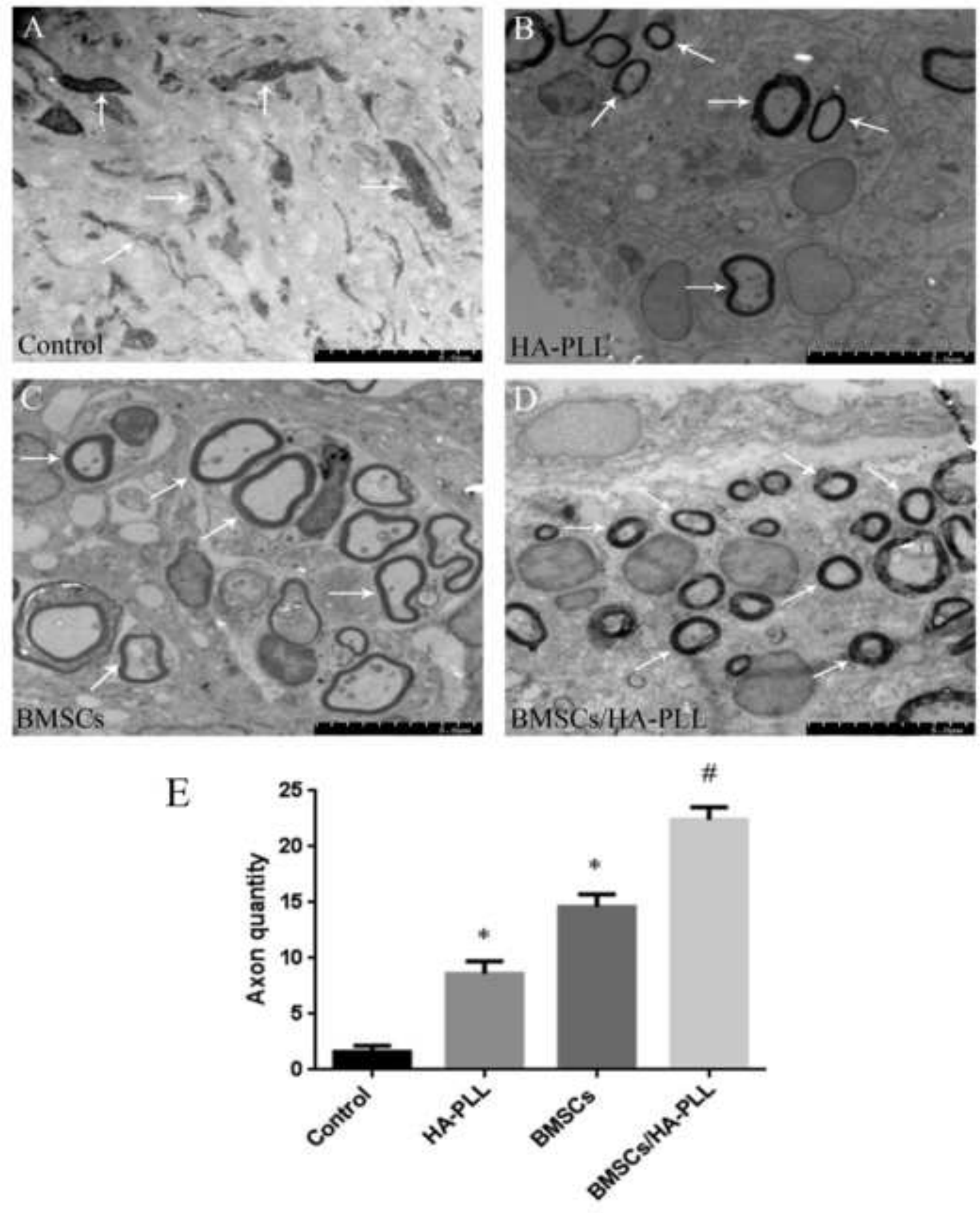

HA-PLE . 


\section{Rat Electrophysiology Latent Period Change}

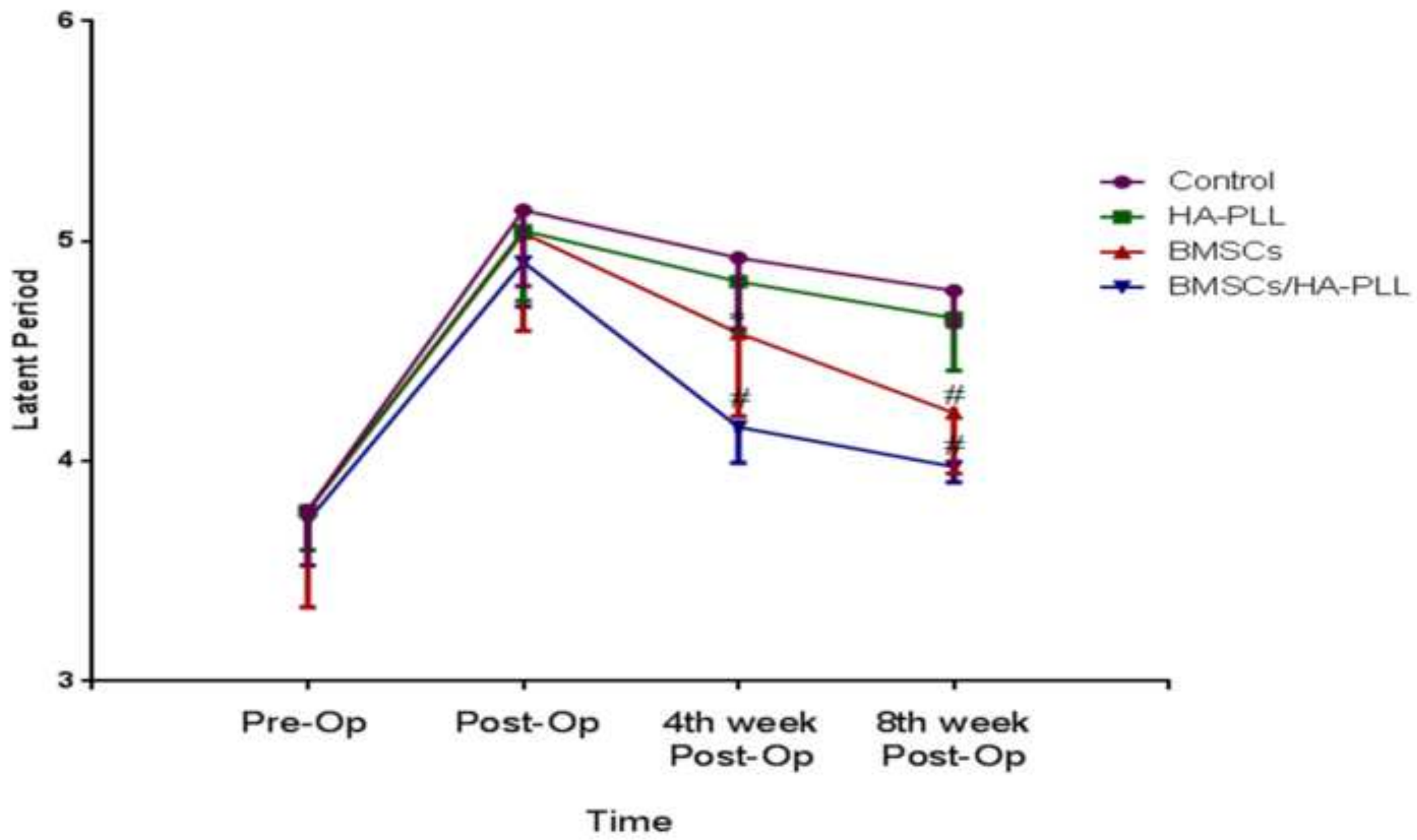




\section{Rat BBB Locomotor Rating Scale}

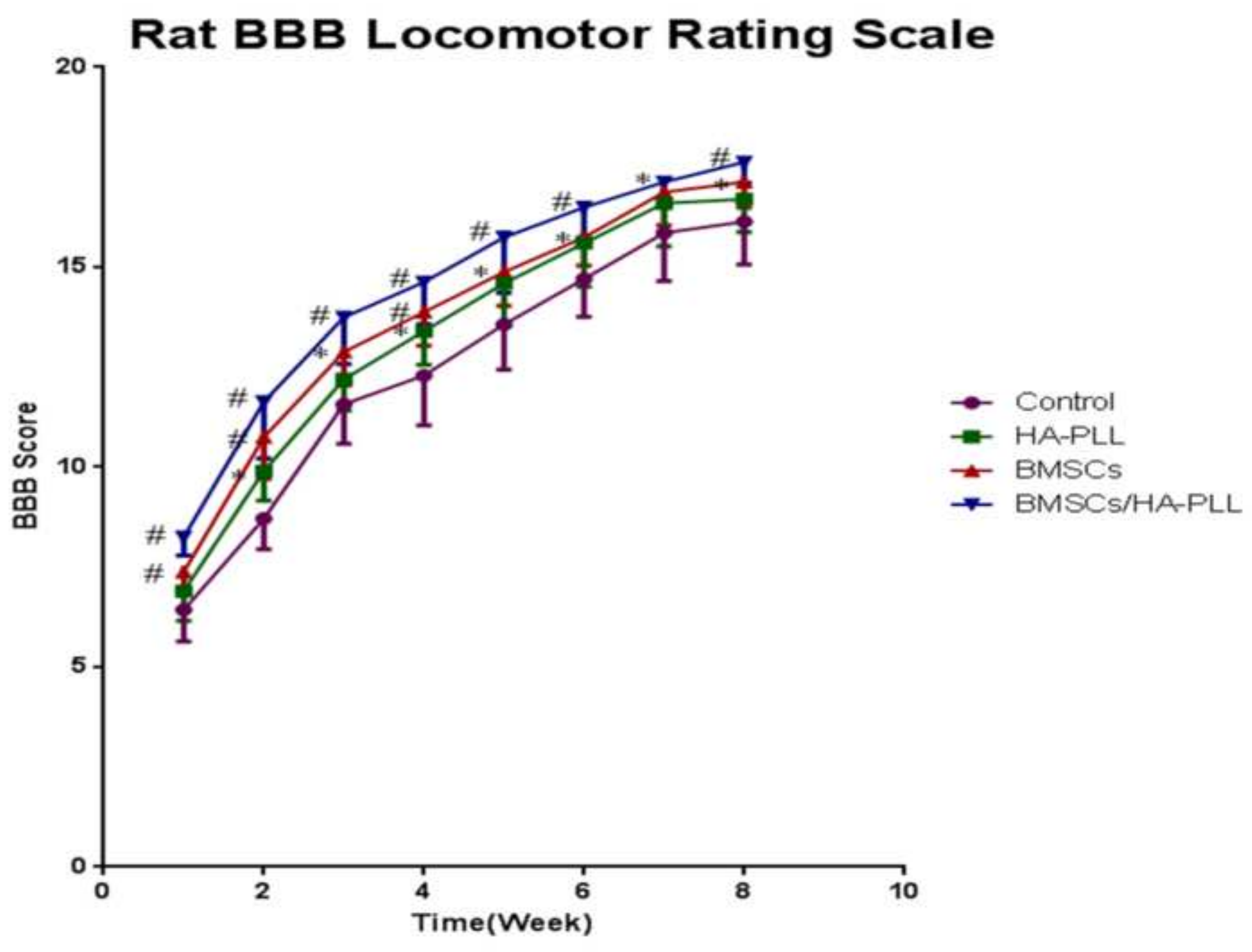

